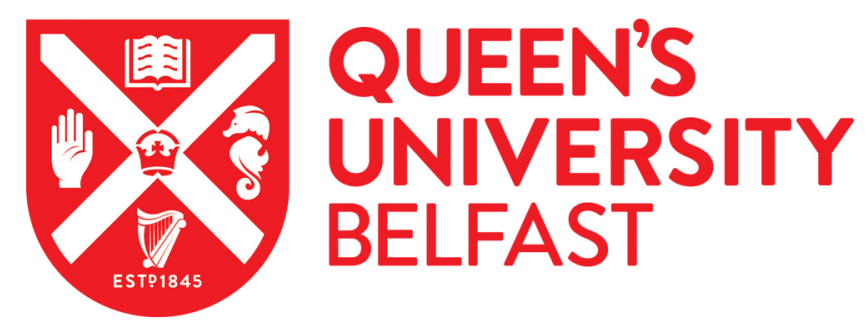

\title{
Pseudomonas aeruginosa Isolates From a Cohort of Mexican Children With Cystic Fibrosis Show Adaptation to a Chronic Phenotype
}

Rosales-Reyes, R., Rodríguez-Alvarado, M., Lezana-Fernández, J. L., Sánchez-Lozano, J. Y., GayossoVázquez, C., Arredondo-Mercado, M. J., Jarillo-Quijada, D., Toledano-Tableros, J. E., Alcántar-Curiel, M. D., Lincopan, N., Vidal, J. E., Lascurain, R., Valvano, M. A., \& Santos-Preciado, J. I. (2020). Pseudomonas aeruginosa Isolates From a Cohort of Mexican Children With Cystic Fibrosis Show Adaptation to a Chronic Phenotype. Pediatric Infectious Disease Journal. https://doi.org/10.1097/INF.0000000000002714

Published in:

Pediatric Infectious Disease Journal

Document Version:

Peer reviewed version

Queen's University Belfast - Research Portal:

Link to publication record in Queen's University Belfast Research Portal

Publisher rights

Copyright 2020 Lippincott, Williams \& Wilkins. This work is made available online in accordance with the publisher's policies. Please refer to any applicable terms of use of the publisher.

\section{General rights}

Copyright for the publications made accessible via the Queen's University Belfast Research Portal is retained by the author(s) and / or other copyright owners and it is a condition of accessing these publications that users recognise and abide by the legal requirements associated with these rights.

\section{Take down policy}

The Research Portal is Queen's institutional repository that provides access to Queen's research output. Every effort has been made to ensure that content in the Research Portal does not infringe any person's rights, or applicable UK laws. If you discover content in the Research Portal that you believe breaches copyright or violates any law, please contact openaccess@qub.ac.uk. 
1 Pseudomonas aeruginosa isolates from a cohort of Mexican children with CF show

2 adaptation to a chronic phenotype

3

4 Roberto Rosales-Reyes, PhD*, Marian Rodríguez-Alvarado, MD ${ }^{\dagger}$, José Luis Lezana-

5 Fernández, $\mathrm{MD}^{\dagger}$, Joselin Yleana Sánchez-Lozano*, Catalina Gayosso-Vázquez, BSc*,

6 Martha Jimena Arredondo-Mercado*, Ma Dolores Jarillo-Quijada, BSc*, José Eduardo

7 Toledano-Tableros, MSc* , María Dolores Alcántar-Curiel, DSc*, Nilton Lincopan, $\mathrm{PhD}^{\ddagger}$,

8 Jorge E. Vidal, $\mathrm{PhD}^{\S}$, Ricardo Lascurain, $\mathrm{DSc}^{\ddagger}$, Miguel A. Valvano, MD` and José Ignacio

9 Santos-Preciado, $\mathrm{MD}^{*}$.

$11{ }^{*}$ Unidad de Investigación en Medicina Experimental, Facultad de Medicina, Universidad

12 Nacional Autónoma de México. Mexico City, Mexico.

13 'Laboratorio de Fisiología Pulmonar, Clinica de Fibrosis Quistica, Hospital Infantil de

14 México Federico Gómez, Mexico City, Mexico.

15 Department of Microbiology, Institute of Biomedical Sciences, University of São Paulo, São

16 Paulo, Brazil.

17 §epartment of Microbiology and Immunology, University of Mississippi Medical Center, 18 Mississipi, USA.

$19{ }^{¥}$ Departamento de Bioquímica, Facultad de Medicina, Universidad Nacional Autónoma de 20 México. Mexico City, Mexico.

21 The Wellcome-Wolfson Institute for Experimental Medicine, Queen's University Belfast, 22 Belfast, United Kingdom. 
1 Address for correspondence: Roberto Rosales-Reyes, DSc, Unidad de Investigación en

2 Medicina Experimental, Facultad de Medicina, Universidad Nacional Autónoma de México.

3 Dr. Bálmis No. 148, Colonia Doctores, Delegación Cuauhtémoc, Postal code: 06726, Phone

$4 \quad+52$ (55) 5623 2670, Fax +52 (55) 5623 2669, email: rrosalesr@ciencias.unam.mx

6 Source of support: This work has been supported in part by the Programa de Apoyo a

7 Proyectos de Investigación e Inovación Tecnológica (UNAM-PAPIIT), Grant No. IN224491

8 to R.L., Grant No. IN221617 to M.D.A.C. and Medical Research Council grant

9 MR/P022480/1 to M.A.V. The authors have no conflict of interest.

11 Key words: Cystic fibrosis, bacterial pathogens, antimicrobial resistance, polymyxin 12 resistance, virulence factors

14 Abbreviated title: $P$. aeruginosa from children with CF are chronicity-inducers

16 Running head title: $P$. aeruginosa in Mexican children with CF 
2 Abstract

3 Background: Long-term persistence of Pseudomonas aeruginosa in the lung of individuals

4 with cystic fibrosis is associated with progressive selection of diverse genotypes and

5 phenotypes. This bacterial adaptation leads to chronic infection, and increased morbidity and

6 mortality. The aim of this study was to establish the prevalence, clonal relatedness,

7 antimicrobial susceptibility and virulence-associated phenotypes of $P$. aeruginosa isolates in

8 a cohort of 50 Mexican children with $\mathrm{CF}$-associated chronic lung infection.

9 Methods: Clonal relatedness of $P$. aeruginosa isolates was verified by pulsed-field gel

10 electrophoresis. The antimicrobial susceptibility was determined by an automated VITEK 2

11 system and/or broth micro-dilution method. Biofilm formation was quantified by the crystal

12 violet method; swarming motility was measured on soft agar, and susceptibility to normal

13 human serum determined by reduction of CFUs.

14 Results: High prevalence of $P$. aeruginosa colonization among Mexican children with CF

15 was confirmed; 20\% (10/49) of clones identified showed a multidrug-resistant phenotype and

$168.2 \%(4 / 49)$ an extensive drug resistance phenotype; $26.5 \%(13 / 49)$ of the isolates were

17 resistant to colistin, $42.9 \%(21 / 49)$ presented a phenotype of adaptation associated with

18 chronic infection, and 79.6\% (39/49) showed increased ability to survive in normal human

19 serum.

20 Conclusions: This cohort of children with cystic fibrosis reveals that colonizing $P$.

21 aeruginosa strains predominantly display resistance to several first-line antibiotics although

22 most isolates were susceptible to meropenem and tobramycin; $42.9 \%$ of isolates showed a

23 phenotype consistent with adaptation to chronic lung infection. 
2 Cystic fibrosis (CF) is an autosomal recessive disease ${ }^{1}$ characterized by multiple organ

3 dysfunction including the lung, gastrointestinal tract, liver, pancreas and male reproductive

4 organs. $^{2}$ Organ dysfunction is associated with mutations in the cystic fibrosis transmembrane

5 conductance regulator (cftr) gene ${ }^{3}$, which modulates chloride, sodium, $\mathrm{HCO}_{3}$ and water

6 transport across epithelial membranes. ${ }^{4}$ In particular, CF lungs have a defective mucociliary

7 clearance that results in airway obstruction by production of thick and dehydrated

8 secretions, ${ }^{2,5}$ which in turn leads to chronic bacterial infections. ${ }^{6}$ Chronic infection and

9 persistent inflammation gradually induce structural lung damage. ${ }^{6}$ Early in life, the lungs of

10 affected children are initially colonized by Haemophilus influenzae and Staphylococcus

11 aureus $^{6-10}$ and progressively acquire $P$. aeruginosa, which increases from $10-30 \%$ at ages 0 -

125 years to $80 \%$ at ages $\geq 18$ years. ${ }^{11}$ With less frequency, the lungs of individuals with $\mathrm{CF}$ are

13 colonized by members of the Burkholderia cepacia complex, Achromobacter xylosoxidans,

14 Stenotrophomonas maltophilia and non-tuberculous mycobacteria. ${ }^{12}$ Although the true

15 incidence of CF in Mexico is unknown, the Mexican Cystic Fibrosis Society ${ }^{13}$ estimates that

16350 children with CF are born every year. Unfortunately, only $15 \%$ of them are detected

17 before the first four years of life, and the others die due to respiratory complications and

18 malnutrition. The life expectancy of children with CF in Mexico is 19 years. Until now, the

19 prevalence of bacterial pathogens associated to pediatric patients with CF was unknown. In

20 this study, we report a cohort of Mexican children with CF-associated lung disease that are

21 mainly colonized by strains of $P$. aeruginosa with phenotypes consistent with bacterial 22 adaptation to chronic infection. 


\section{$1 \quad$ Material and Methods}

\section{Sample collection and bacterial identification}

3 This study was approved by the Institutional Review Board (IRB) of the School of Medicine

4 at UNAM (Protocol FMED/CI/RGG/022/2016). Bacterial strains were isolated from lung

5 infections in 50 subjects ( 0 to 18 years of age) that were diagnosed with CF by screening of

6 the immunoreactive trypsinogen and by sweat chloride test and followed at the CF clinic at

7 “Hospital Infantil de México Federico Gómez” (HIMFG), Mexico City, Mexico from August

82016 to January 2018. The parents of the children that accepted to participate in the study

9 signed a letter of consent authorizing the collection of samples and the laboratory procedures

10 to identify bacterial pathogens. The staff of the CF clinic collected information on each

11 patient including name, age, sex, place of residency, pulmonary function and pancreatic

12 function, sweat chloride test, and mutations associated to $c f t r$ gene status. Patient samples

13 were collected as part of routine care based on scheduled appointments every 3-6 months

14 (however, some patients do not always assist to their scheduled appointments at the CF

15 clinic). Samples were handled anonymously. Sputum samples or cough swabs (children of

$16<2$ years of age) were transported to our laboratory and processed immediately. Briefly,

17 sputum samples were dissolved with sputolysin weight/volume (1:1) (Merk-Millipore)

18 during $30 \mathrm{~min}$ at $37^{\circ} \mathrm{C}$. Dissolved sputum and cough swabs were subsequently inoculated

19 onto MacConkey, salt and mannitol, chocolate, blood (DIBICO) and cetrimide (Becton

20 Dickinson) agar media plates. Inoculated plates were incubated aerobically at $37^{\circ} \mathrm{C}$ for up 48

21 h. Chocolate and blood agar plates were also incubated under microaerophilic conditions by

$22 \quad 24 \mathrm{~h}$ at $37^{\circ} \mathrm{C}$. Initial bacterial identification was performed by standard microbiological 
1 methods, and the species confirmed with the API20NE (bioMerieux®SA) system. All

2 samples were stored at $-70^{\circ} \mathrm{C}$ until analysis.

3

4 Pulsed-field gel electrophoresis (PFGE)

5 Pulsed-field gel electrophoresis (PFGE) was used to genotype bacterial isolates. Bacterial

6 genomic DNA was prepared as previously described. ${ }^{14}$ For P. aeruginosa, the genomic DNA

7 was digested with SpeI, $X b a \mathrm{I}$ (Invitrogen) and ApaI (New England Biolabs, every, MA).

8 Digested DNAs were resolved by PFGE analysis using a Gene Path system (BioRad $\left.{ }^{\circledR}\right)$. The

9 relatedness between clinical isolates was determined using the Tenover criteria ${ }^{15}$ and Dice

10 coefficient. ${ }^{16}$ Every isolate yielding a correlation $>85 \%$ was deemed as member of the same

11 clone.

12

13 Antimicrobial susceptibility testing

$14 P$. aeruginosa isolates were tested for susceptibility to amikacin, aztreonam, cefazolin, 15 cefepime, gentamicin, meropenem, piperacillin/tazobactam and tobramycin using the 16 VITEK 2 system (bioMerieux®SA). The susceptibility to colistin and polymyxin B was 17 determined by broth microdilution according to Clinical Laboratory Standards Institute 18 (CLSI) guidelines 2019. ${ }^{17}$ P. aeruginosa ATCC 27853 and Escherichia coli ATCC 25922 19 were used as controls.

20

\section{Pigment and alginate production}


1 Pigment and alginate production by $P$. aeruginosa isolates were determined on cetrimide

2 agar as described. ${ }^{18}$ Alginate production was observed on cetrimide or MacConkey agar 3 plates.

\section{Biofilm assays}

6 Biofilm production was evaluated on polystyrene tubes, as previously described. ${ }^{14} P$. 7 aeruginosa PAO1, kindly donated by Dr. Maria del Rosario Morales-Espinoza from the 8 "Facultad de Medicina, Universidad Nacional Autónoma de México", was used as reference 9 strain. $^{19}$

\section{Motility assays}

12 For swarming motility, $P$. aeruginosa clinical isolates were grown in $5 \mathrm{ml}$ Luria broth (LB)

13 at $37^{\circ} \mathrm{C}, 180 \mathrm{RPM}$ for $24 \mathrm{~h}$. Bacterial cultures were adjusted to $1 \times 10^{7}$ cells $/ \mathrm{ml}$ in fresh LB. 14 Ten- $\mu 1$ aliquots were carefully inoculated on a semi-solid LB plates containing $0.3 \%$ of agar 15 (Bacto), once the agar plates with bacteria was dried, the plates were incubated at $37^{\circ} \mathrm{C}$ during 16 exactly $24 \mathrm{~h}$. The diameter of the motility zone was measured. Acinetobacter baumannii 17 ATCC 17965 and Salmonella typhimurium ATCC 14028 were used as non-motile and motile 18 control strains, respectively.

\section{Serum resistance assay}

21 Survival of $P$. aeruginosa isolates in normal human serum (NHS) was evaluated as 22 previously reported. ${ }^{14}$ Briefly, every P. aeruginosa isolate was grown in Müller Hinton (MH) 23 broth overnight. The bacterial culture was adjusted to $1 \times 10^{7}$ cells $/ \mathrm{ml}$ using $40 \%$ of normal 
1 human serum (NHS) (Cedarlane Laboratories Limited, Ontario, Canada) or with $40 \%$ of

2 heat-inactivated NHS (HIS). Samples were incubated during $3 \mathrm{~h}$ at $37^{\circ} \mathrm{C}$ without shaking.

3 After incubation, the number of surviving bacteria in each sample was determined by serial

4 dilution and plating in $\mathrm{MH}$-agar and incubated at $37^{\circ} \mathrm{C}$ for $18 \mathrm{~h}$. The survival of $P$. aeruginosa

5 to NHS activity was calculated with the formula: \% survival $=($ CFUs-NHS / CFUs-HIS $)$

$6 * 100$. The efficiency of NHS and HIS were assessed with Salmonella enterica Serovar Typhi

$7 \quad 9: 12:$ Vid as a sensitive strain to NHS.

9 Results

10 Prevalence of $\boldsymbol{P}$. aeruginosa in pediatric individuals with Cystic Fibrosis

11 We enrolled 50 subjects (0-18 years of age) attending the CF clinic; $52.0 \%(26 / 50)$ were

12 males. Thirty individuals of this cohort had documented mutations within the cftr gene, while

13 the other 20 did not have a sequenced cftr. Of sequenced genes, $26.6 \%(8 / 30)$ carried the

14 most frequent homozygotic mutation: $\Delta \mathrm{F} 508$, followed by $36.6 \%(11 / 30)$ carrying $\Delta \mathrm{F} 508 / \mathrm{x}$,

$1510.0 \%(3 / 30) \Delta \mathrm{F} 508 /$ other mutation and $26.6 \%(8 / 30)$ carrying other types of mutations

16 (Table 1). Twenty-one patients were chronically infected by $P$. aeruginos $a$ at the time of

17 enrollment (defined as at least three of six positive cultures over one year), 13 had a history

18 of intermittent infection (defined as one of six positive culture), and 16 did not have a positive

19 culture (Table 2, Supplementary Figure 1A). Two patients died during the study period. The

20 patients with chronic infection and lower lung function were older (Table 2, Supplementary

21 Figure 1A and 1B). Further, during the study, we detected 10/16 patients with good lung

22 function in whom $P$. aeruginosa had not been previously identified (Table 2 and

23 Supplementary Figure 1A and 1B). 
1 We analyzed 106 sputum samples collected during the medical assessment (50 were obtained

2 at time of patient enrollment, 33 from a second appointment, 19 from a third and 3 from a

3 fourth appointment, respectively). We identified the presence of one bacterial pathogen in

$450.9 \%(54 / 106)$ samples, two bacterial pathogens in $29.2 \%(31 / 106)$, three in $6.6 \%(7 / 106)$

5 and four in $1.9 \%(2 / 106)$. No pathogenic bacteria were isolated in $11.3 \%(12 / 106)$ samples.

6 We identified 160 bacterial species; 47.5\% were P. aeruginosa, 31.9\% Staphylococcus

7 aureus, 9.4\% Escherichia coli, 1.9\% coagulase-negative Staphylococci, 1.9\% group A

8 Streptococcus, 1.3\% group B Streptococcus, 1.3\% Serratia marcescens, 1.3\% Klebsiella

9 pneumoniae, 1.3\% Klebsiella oxytoca, 1.3\% Enterobacter cloacae, $0.6 \%$ group C

10 Streptococcus and 0.6\% Burkholderia cepacia (Figure 1A and Table 2). P. aeruginosa was

11 the most frequently isolated pathogen from samples of individuals ranging from $0-18$ years

12 of age, and Staphylococcus aureus was the second most frequent pathogen in individuals

13 ranging from 6-12 years of age (Figure 1A and 1B).

\section{Genotyping of $P$. aeruginos $a$ isolates}

16 we analyzed 76 P. aeruginosa isolates by PFGE to investigate the genetic relatedness of 17 isolates and determine a possible clonal dissemination within individuals attending the

18 HIMFG (Figure 2). Forty-nine unrelated clones were identified, indicating unique 19 colonization events, while one of the isolates was non-PFGE typeable. Of the related clones 20 present in different individuals, Psa01 was isolated from individual CF002 and CF003, 21 Psa02 from CF003 and CF014, and Psa17 from CF013 and CF028. Twelve subjects (24\%)

22 were colonized by different clones of $P$. aeruginosa. For example, individual CF002 was 23 colonized by $P s a 01$ and $P s a 18$, CF003 by Psa01, Psa02 and Psa40, whereas individual 
1 CF008 was colonized by strains $P s a 05$ and $P s a 34$. The rest of combinations are presented in

2 Figure 2.

4 Antibiotic susceptibility to $P$. aeruginosa isolates

5 One representative member of each $P$. aeruginosa PFGE clone was assessed for the

6 antimicrobial susceptibility. We did not consider in this analysis the intrinsic resistance

7 exhibited by P. aeruginosa. ${ }^{17}$ Twenty \% (10/49) of these clones presented a multidrug-

8 resistance $(\mathrm{MDR})$ phenotype (non-susceptible to $\geq$ one agent in $\geq$ three antimicrobial

9 categories $)^{20}$ whereas $8.1 \%(4 / 49)$ showed an extensively drug resistance (XDR) phenotype

10 (non-susceptible to $\geq$ one agent in all but $\geq$ two antimicrobial categories) ${ }^{20}$ (Table 3 and

11 Supplementary Figure 1). We also found that 26.5\% (13/49) of strains were resistant to the

12 last resort antibiotic colistin and $10.2 \%(5 / 49)$ to polymyxin B.

14 Adaptation to a chronic infection phenotype by clones of $\boldsymbol{P}$. aeruginosa

15 During the course of lung infection in people with CF, $P$. aeruginosa undergoes adaptive

16 changes including reduced flagella and pili expression, reduced production and release of

17 some proteases and pyoverdine, and downregulation of the type 3 secretion system. ${ }^{21}$ Other

18 changes involve overexpression of alginate, increased biofilm formation, and increased

19 antibiotic resistance. ${ }^{21}$ These changes are characteristic of $P$. aeruginosa strains establishing

20 chronic infections that persist until the end of the patient's life. ${ }^{22}$ In Table 3 , we show that

$2142.9 \%(21 / 49)$ of representative members of $P$. aeruginosa clones were high biofilm

22 producers, $48.9 \%(24 / 49)$ of them produced moderated biofilm and $8.2 \%(4 / 49)$ were weak

23 biofilm producers. The quantification of bacterial motility shows that only $10.2 \%(5 / 49)$ were

24 non-motile, $81.6 \%(40 / 49)$ had reduced motility and only $8.2 \%(4 / 49)$ were motile. $34.7 \%$ 
1 (17/49) of the isolates produced alginate, $69.4 \%(34 / 49)$ produced pyoverdine, $16.3 \%(8 / 49)$

2 pyocyanin and $8.2 \%$ (4/49) pyomelanin (Table 3). Particularly, 21/49 clones; Psa03, Psa05,

3 Psa06, Psa10, Psa12, Psa13, Psa17, Psa18, Psa26, Psa28, Psa30, Psa31, Psa33, Psa34,

$4 \quad$ Psa35, Psa37, Psa40, Psa42, Psa44, Psa47 and Psa49 have at least three phenotypes

5 associated with chronic lung infection (biofilm production, decreased motility, alginate

6 production and MDR/XDR resistance). PsaNT was not included in the analysis. Clones

7 Psa02, Psa04, Psa07, Psa09, Psa11, Psa15, Psa16, Psa20, Psa21, Psa22, Psa23, Psa24,

$8 \quad$ Psa25, Psa27, Psa29, Psa32, Psa36, Psa38, Psa41, Psa43, Psa45 and Psa48 showed two

9 phenotypes associated with chronic lung infection. Clone Psa04 was isolated three times

10 from the same patient, Psa06 four times, Psa09 two times, Psa14 two times, Psa17 three

11 times in the same patient and two times in an unrelated patient, Psa23 two times, Psa24 two

12 times, Psa25 three times, Psa31 two times, and PsaNT two times, suggesting these strains

13 persisted in the lung environment allowing them to persist over the time (Figure 2).

14 Nevertheless, clone Psa01 was isolated three times (two times in CF002 and one in CF003)

15 and Psa14 (two times in CF048) that did not show a characteristic phenotype of adaptation.

16 The remaining clones isolated showed one phenotype associated with persistence in the lung

17 environment. In summary, $42.9 \%(21 / 49)$ of these clones mentioned above showed a

18 phenotype characteristic of bacteria establishing chronic infections.

\section{$20 \quad P$. aeruginosa survives in normal human serum}

21 Bacteremia by $P$. aeruginosa has been demonstrated in individuals with $\mathrm{CF}^{23}$ To determine

22 the ability of clones of $P$. aeruginosa isolated from our pediatric cohort to survive the

23 bactericidal activity of normal human serum (NHS), we performed a conventional assay to

24 determine their susceptibility to NHS. ${ }^{24}$ Our results demonstrated that $28.6 \%(14 / 49)$ of the 
1 clones were highly resistant to the NHS ( $\geq 60.0 \%$ of survival), $22.4 \%(11 / 49)$ showed

2 moderated resistance ( $\geq 20.0 \%$ but $<60 \%$ of survival), $24.4 \%(12 / 40)$ showed low resistance

3 to NHS activity ( $<20.0 \%$ but $\geq 1.0 \%$ of survival) and $24.4 \%(12 / 29)$ were highly susceptible

4 to HNS activity ( $<1.0 \%$ of survival) (Table 3 and Supplementary Figure 2).

\section{Discussion}

7 Prior to this study, the incidence of bacterial pathogens associated with respiratory 8 complications in Mexican children with CF was unknown. In this study, we found that $P$.

9 aeruginosa was the most prevalent pathogen associated with the lung micro-environment of

10 individuals with $\mathrm{CF}$. The $P$. aeruginosa adaptation to this adverse lung environment is key

11 for bacterial persistence. ${ }^{25}$ It is believed that the continuous and frequent rate of mutation

12 leads to the adaptation of $P$. aeruginosa to the CF lung environment and results in phenotypes

13 characteristic of chronic infection, they exhibit reduced bacterial motility, increased biofilms

14 formation, and increased antimicrobial resistance. ${ }^{21,26}$ Consistent with this notion, $32 \%$ of $P$.

15 aeruginosa clones in our study had reduced motility ( $<50 \%$ of PAO1 motility), $6 \%$ were non-

16 motile, $44 \%$ were higher biofilm producers (more than PAO1) and $34 \%$ produced alginate.

17 However, 12.2\% (6/28) of isolated clones persisted in the lung without a clear-cut chronic

18 phenotype, suggesting that other mechanism of adaptation could be involved. The possibility

19 also exists that these children are directly exposed in their households to $P$. aeruginosa strains

20 and given their impaired lung activity, they become colonized. Unfortunately, two

21 individuals (CF008 and CF014) died during this study; CF008 was infected by Psa05 and

22 Psa34, isolates that showing a classical adaptation phenotype to chronic infection (e.g.,

23 MDR, higher biofilm production, reduced motility, alginate producer but susceptible to 
1 normal human serum), whereas CF014 was infected by Psa02 and Psa09, clones with

2 moderated adaptation phenotype (e.g., MDR, biofilm producer, non-motile, alginate

3 producer and moderated resistance to normal human serum). These two clones were not

4 isolated from any other patient.

5 Our study underscores the importance of maintaining epidemiological surveillance of the

6 bacterial colonization in CF patients in order to avoid or limit the possible spreading of $P$.

7 aeruginosa among these patients in the hospital environment. ${ }^{27-29} \mathrm{We}$ found that shared

8 clones of $P$. aeruginosa were not associated with geographic distribution of the subjects;

9 therefore, a common source of contamination is unlikely. During clinical assessment, each

10 CF subject is seen, one at a time, in separate examining rooms with exhaustive cleaning

11 between visits. However, we suspect that the spreading of clones between the subjects

12 enrolled could have occurred in common areas of the hospital in which they could gather.

13 Bloodstream infections caused by $P$. aeruginosa may be an important risk factor associated

14 to mortality in CF patients. ${ }^{30,31}$ Our results show that fourteen clones are highly resistant to

15 anti-bacterial activity of normal human serum while nine strains presented moderate

16 resistance. However, no correlation with lung function or antimicrobial resistance was

17 detected. Overall, the identification of clones of $P$. aeruginosa that present phenotypes

18 associated with chronic lung infections of pediatric people with CF help us understand 19 pathogenic mechanisms associated with the establishment of chronic infection.

\section{Conclusions}

22 This is the first study reporting the bacterial colonization of Mexican children with CF and

23 most surprisingly that $42.9 \%$ of the patients were colonized with a $P$. aeruginosa phenotype

24 associated with chronic infection and an ability to survive the bactericidal effect of normal 
1 human serum. Rapid bacterial detection in the respiratory secretions of newly diagnosed

2 patients with $\mathrm{CF}$ is of paramount importance for the early treatment to prevent the irreversible

3 pulmonary damage. Our study underscore the importance of prospectively characterizing the

4 associated respiratory bacterial pathogens beyond a simple identification of genus and

5 species. As we have clearly shown, while $P$ aeruginosa is a common colonizer, the simple

6 phenotype does not predict its relationship with chronic lung infection. We believe that there

7 is a need for the development of simpler diagnostic test to identify those phenotypes

8 associated with chronic lung infections.

10 Figure legends

12 Figure 1. Frequency of bacterial pathogens isolated from sputum samples of pediatric

13 patients with CF. The samples were analyzed for frequency of bacterial pathogens isolated

14 (A) and by frequency of bacterial pathogens identified over a range of ages from 1-18 years 15 of age (B).

16

17 Figure 2. Dendrogram generated from the analysis of $76 \boldsymbol{P}$. aeruginosa clinical isolates

18 from pediatric patients with CF. Isolates were grouped in 49 different clones. One PFGE

19 profile by clone was used to construct the dendrogram. NT, non-typeable. Frequency of

20 isolates by clone is indicated (\# isolates). The patient column indicates the patient in which

21 a clone is isolated. Patients colonized by more than one clone are underlined. The number in

22 parenthesis indicates the frequency of clone identification. ${ }^{*}$ Clones identified in different

23 patients. Dashed line indicates the $70 \%$ similarity level used in the cluster designation.

24 Clustering groups are indicated. 


\section{Acknowledgments}

3 We thank to Mariana Martínez-Parrilla, Ana Leticia Delgado-Ramírez, Paola Garza-

4 Villafuerte and Fernanda Sánchez-Rios for technical support. This work has been supported 5 in part by the Programa de Apoyo a Proyectos de Investigación e Inovación Tecnológica 6 (UNAM-PAPIIT), Grant No. IN224491 to R.L., Grant No. IN221617 to M.D.A.C., and

7 Medical Research Council grant MR/P022480/1 to M.A.V. N.L. is a research fellow of

8 Conselho Nacional de Desenvolvimento Científico e Tecnológico (CNPq 312249/2017-9).

\section{Conflict of interest statement}

11 The authors have no conflict of interest.

\section{References}

14 1. Moskowitz SM, Chmiel JF, Sternen DL, et al. Clinical practice and genetic

15 counseling for cystic fibrosis and CFTR-related disorders. Genet Med. 2008;10:851-

16868.

17 2. Boyle MP. Adult Cystic Fibrosis. JAMA. 2007;298:1787-1793.

18 3. O’Sullivan BP, Freedman SD. Cystic fibrosis. Lancet. 2009;373:1891-1904.

19 4. Dechecchi MC, Tamanini A, Cabrini G. Molecular basis of cystic fibrosis: from

$20 \quad$ bench to bedside. Ann Transl Med. 2018;6:334.

21 5. Mogayzel PJ, Naureckas ET, Robinson KA, et al. Cystic Fibrosis Pulmonary

22 Guidelines. Am J Respir Crit Care Med. 2013;187:680-689.

23 6. Boutin S, Dalpke AH. Acquisition and adaptation of the airway microbiota in the 24 early life of cystic fibrosis patients. Mol Cell Pediatr. 2017;4:1. 
1 7. Cox MJ, Allgaier M, Taylor B, et al. Airway Microbiota and Pathogen Abundance in $2 \quad$ Age-Stratified Cystic Fibrosis Patients. PLoS One. 2010;5:e11044.

3 8. Mott LS, Park J, Murray CP, et al. Progression of early structural lung disease in 4 young children with cystic fibrosis assessed using CT. Thorax. 2012;67:509 LP $5 \quad 516$.

69 . Ramsey KA, Ranganathan S, Park J, et al. Early Respiratory Infection Is Associated

9 10. Stick S, Tiddens H, Aurora P, et al. Early intervention studies in infants and

12 11. Rosenfeld M, Gibson RL, McNamara S, et al. Early pulmonary infection, 13 inflammation, and clinical outcomes in infants with cystic fibrosis. Pediatr Pulmonol. 2001;32:356-366.

15 12. Fodor AA, Klem ER, Gilpin DF, et al. The Adult Cystic Fibrosis Airway Microbiota 16 Is Stable over Time and Infection Type, and Highly Resilient to Antibiotic

21 14. Rosales-Reyes R, Gayosso-Vázquez C, Fernández-Vázquez JL, et al. Virulence profiles and innate immune responses against highly lethal, multidrug-resistant nosocomial isolates of Acinetobacter baumannii from a tertiary care hospital in Mexico. PLoS One. 2017;12. 
1 15. Tenover FC, Arbeit RD, Goering R V, et al. Interpreting chromosomal DNA

2 restriction patterns produced by pulsed-field gel electrophoresis: criteria for bacterial

3 strain typing. J Clin Microbiol. 1995;33:2233 LP - 2239.

4 16. Dice LR. Measures of the Amount of Ecologic Association Between Species.

$5 \quad$ Ecology. 1945;26:297-302.

6 17. CLSI. M100. Performance Standards for Antimicrobial Susceptibility Testing. 28h

7 ed. CLSI Supplement. 2018;CLSI docum.

8 18. Jácome, Paula Regina Luna de Araújo, Alves LR, Cabral AB, Lopes ACS, Maciel

9 MAV. Phenotypic and molecular characterization of antimicrobial resistance and

10 virulence factors in Pseudomonas aeruginosa clinical isolates from Recife, State of

11 Pernambuco, Brazil. Rev Soc Bras Med Trop. 2012;45:707-712.

12 19. Stover CK, Pham XQ, Erwin AL, et al. Complete genome sequence of Pseudomonas

13 aeruginosa PAO1, an opportunistic pathogen. Nature. 2000;406:959-964.

14 20. Magiorakos A-P, Srinivasan A, Carey RB, et al. Multidrug-resistant, extensively

15 drug-resistant and pandrug-resistant bacteria: an international expert proposal for

16 interim standard definitions for acquired resistance. Clin Microbiol Infect.

$17 \quad 2012 ; 18: 268-281$.

18 21. Sousa AM, Pereira MO. Pseudomonas aeruginosa diversification during infection

19 development in cystic fibrosis Lungs-A review. Pathogens. 2014;3:680-703.

20 22. Jolivet-Gougeon A, Kovacs B, Le Gall-David S, et al. Bacterial hypermutation:

21 clinical implications. J Med Microbiol. 2011;60:563-573.

22 23. Waters V, Smyth A. Cystic fibrosis microbiology: Advances in antimicrobial

23 therapy. J Cyst Fibros. 2015;14:551-560.

24 24. McCarthy MM, Rourk MH, Spock A. Bacteremia in Patients with Cystic Fibrosis. 
Clin Pediatr (Phila). 1980;19:746-748.

2 25. Smith EE, Buckley DG, Wu Z, et al. Genetic adaptation by Pseudomonas aeruginosa to the airways of cystic fibrosis patients. Proc Natl Acad Sci US A. 2006;103:8487-8492.

5 26. Winstanley C, O’Brien S, Brockhurst MA. Pseudomonas aeruginosa Evolutionary

11 28. Kidd TJ, Magalhães RJS, Paynter S, et al. The social network of cystic fibrosis

27. Wee BA, Tai AS, Sherrard LJ, et al. Whole genome sequencing reveals the emergence of a Pseudomonas aeruginosa shared strain sub-lineage among patients treated within a single cystic fibrosis centre. BMC Genomics. 2018;19:644. centre care and shared Pseudomonas aeruginosa strain infection: A cross-sectional analysis. Lancet Respir Med. 2015;3:640-650.

29. Pedersen SS, Koch C, Heiby N, Rosendal K. An epidemic spread of multiresistant Pseudomonas aeruginosa in a cystic fibrosis centre. J Antimicrob Chemother. 1986;17:505-516.

30. Zhang Q, Smith JC, Zhu Q, Guo Z, MacDonald NE. A five-year review of Pseudomonas aeruginosa bacteremia in children hospitalized at a single center in southern China. Int J Infect Dis. 2012;16:e628-e632.

31. Cargill J, Etherington C, Peckham D, Conway S, Denton M. Bloodstream infections in cystic fibrosis: Nine years of experience in both adults and children. $J$ Cyst Fibros. 2012;11:337-339. 
2 Figure 1. Frequency of bacterial pathogens isolated from sputum samples of pediatric

3 patients with CF. The samples were analyzed for frequency of bacterial pathogens isolated

4 (A) and by frequency of bacterial pathogens identified over a range of ages from 1-18 years 5 of age (B).

6

7 Figure 2. Dendrogram generated from the analysis of $76 P$. aeruginosa clinical isolates

8 from pediatric patients with CF. Isolates were grouped in 49 different clones. One PFGE

9 profile by clone was used to construct the dendrogram. NT, non-typeable. Frequency of

10 isolates by clone is indicated (\# isolates). The patient column indicates the patient in which

11 a clone is isolated. Patients colonized by more than one clone are underlined. The number in

12 parenthesis indicates the frequency of clone identification. *Clones identified in different

13 patients. Dashed line indicates the $70 \%$ similarity level used in the cluster designation.

14 Clustering groups are indicated. 
Figure 1. Frequency of bacterial pathogens isolated from sputum samples of pediatric patients with $\mathrm{CF}$.

A

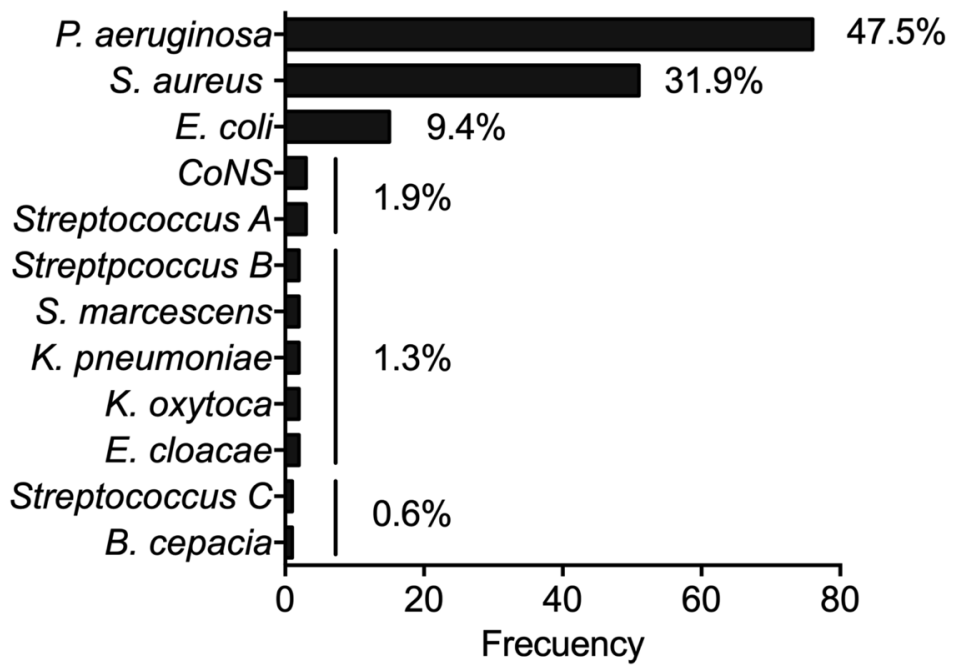

$\mathrm{B}$
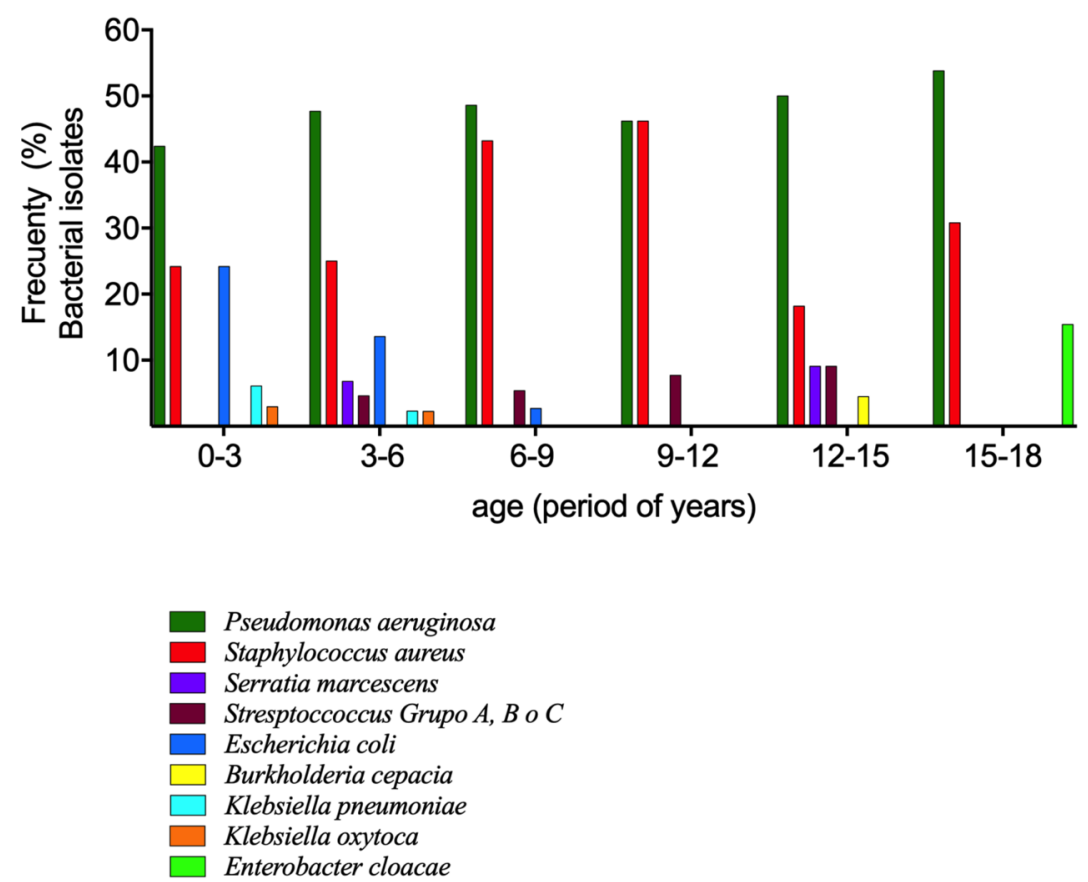
Figure 2. Dendrogram generated from the analysis of $76 P$. aeruginosa clinical isolates from pediatric patients with $\mathrm{CF}$.

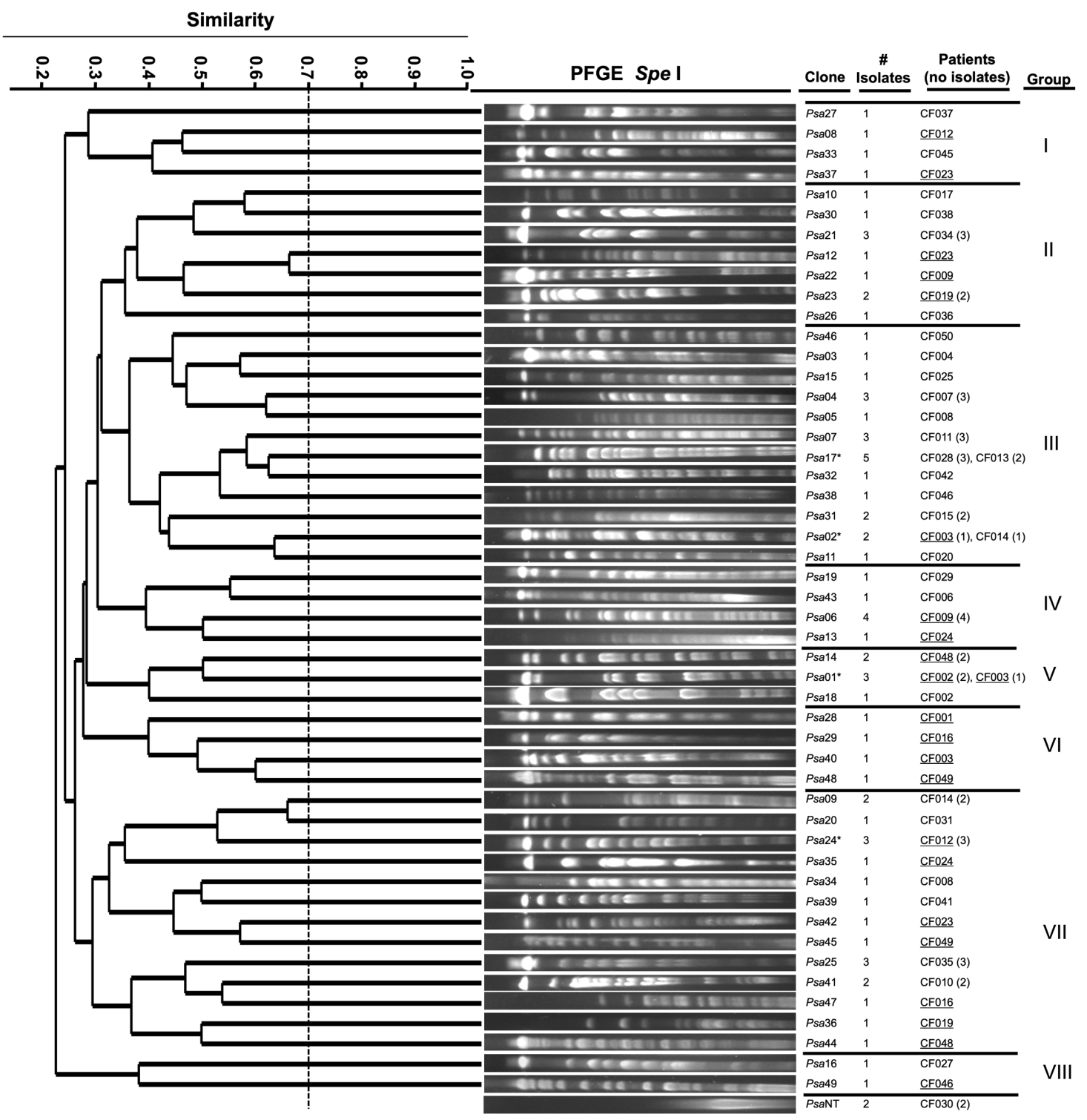


Table1. Demographic and clinical characteristics of enrolled patients.

\begin{tabular}{|c|c|c|c|c|c|c|c|c|c|c|c|c|}
\hline 营 & 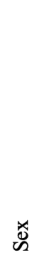 & 芯 & 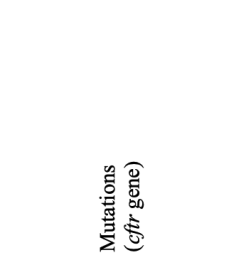 & 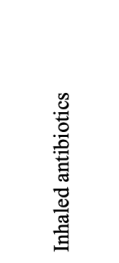 & 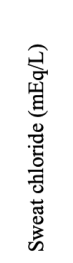 & 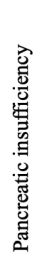 & 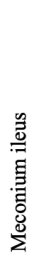 & 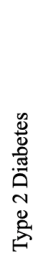 & 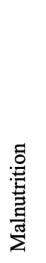 & 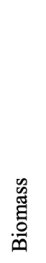 & $\begin{array}{l}\text { 音 } \\
\text { हn }\end{array}$ & 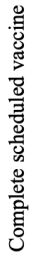 \\
\hline CF001 & $\mathrm{F}$ & CDMX & $\Delta \mathrm{F} 508 / \mathrm{X}$ & - & 82.0 & & & & & & $\mathrm{Y}$ & $\mathrm{Y}$ \\
\hline CF002 & $\mathrm{F}$ & CDMX & $\Delta \mathrm{F} 508 / \mathrm{X}$ & тов & 113.0 & $\mathrm{Y}$ & $\mathrm{Y}$ & $\mathrm{Y}$ & & & & $\mathrm{Y}$ \\
\hline CF003 & $\mathrm{F}$ & MOR & $-1-$ & - & 108.0 & $\mathrm{Y}$ & & & $\mathrm{Y}$ & & & $\mathrm{Y}$ \\
\hline CF004 & M & OAX & $\Delta \mathrm{I} 507 / 165-\mathrm{G}>\mathrm{A}$ & TOB & 93.0 & $\mathrm{Y}$ & & & & & & $\mathrm{Y}$ \\
\hline CF005 & $\mathrm{F}$ & CDMX & $\Delta \mathrm{F} 508 / \mathrm{S} 945 \mathrm{~L}$ & - & 69.0 & & & & & & & \\
\hline CF006 & M & DGO & W1089X / E588X & CXM & 88.0 & $\mathrm{Y}$ & & & $\mathrm{Y}$ & & & $\mathrm{Y}$ \\
\hline CF007 & M & EMEX & $-1-$ & - & 85.0 & $\mathrm{Y}$ & & & $\mathrm{Y}$ & & & $\mathrm{Y}$ \\
\hline $\mathrm{CF} 008 \dagger$ & $\mathrm{F}$ & EMEX & $\Delta \mathrm{F} 508 / \Delta \mathrm{F} 508$ & TOB & 81.0 & $\mathrm{Y}$ & & & $\mathrm{Y}$ & & $\mathrm{Y}$ & \\
\hline CF009 & M & EMEX & $\Delta \mathrm{F} 508 / \Delta \mathrm{F} 508$ & ТОВ & 84.0 & $\mathrm{Y}$ & & & $\mathrm{Y}$ & & $\mathrm{Y}$ & $\mathrm{Y}$ \\
\hline CF010 & $\mathrm{F}$ & CDMX & $\Delta \mathrm{F} 508 / \mathrm{A} 455 \mathrm{E}$ & AZM & 81.0 & $\mathrm{Y}$ & & & $\mathrm{Y}$ & & $\mathrm{Y}$ & $\mathrm{Y}$ \\
\hline CF011 & M & GTO & $\Delta \mathrm{F} 508 / \Delta \mathrm{F} 508$ & - & 83.0 & $\mathrm{Y}$ & & & $\mathrm{Y}$ & $\mathrm{Y}$ & & $\mathrm{Y}$ \\
\hline CF012 & M & PUE & $\Delta \mathrm{F} 508 / \Delta \mathrm{F} 508$ & AMK & 103.0 & $\mathrm{Y}$ & & & $\mathrm{Y}$ & $\mathrm{Y}$ & & $\mathrm{Y}$ \\
\hline CF013 & M & CDMX & $\Delta \mathrm{F} 508 / \mathrm{X}$ & AMX & 104.0 & $\mathrm{Y}$ & & & & & & \\
\hline CF014† & $\mathrm{F}$ & CDMX & $\Delta \mathrm{F} 508 / \mathrm{X}$ & тов & 106.0 & $\mathrm{Y}$ & & & $\mathrm{Y}$ & & & $\mathrm{Y}$ \\
\hline CF015 & $\mathrm{F}$ & HGO & G542 / X & ТОВ & 93.0 & $\mathrm{Y}$ & & & & & & $\mathrm{Y}$ \\
\hline CF016 & M & GTO & $\Delta \mathrm{I} 507 / \mathrm{X}$ & TOB & 95.0 & $\mathrm{Y}$ & & & & & & $\mathrm{Y}$ \\
\hline CF017 & $\mathrm{F}$ & EMEX & $\Delta \mathrm{F} 508 / \Delta \mathrm{F} 508$ & - & 96.0 & $\mathrm{Y}$ & & & & & & $\mathrm{Y}$ \\
\hline CF018 & $\mathrm{F}$ & MOR & $-1-$ & тов & 89.0 & $\mathrm{Y}$ & & & & & & $\mathrm{Y}$ \\
\hline CF019 & M & CDMX & $\Delta \mathrm{F} 508 / \mathrm{X}$ & TOB & 96.0 & $\mathrm{Y}$ & $\mathrm{Y}$ & & $\mathrm{Y}$ & & & $\mathrm{Y}$ \\
\hline CF020 & M & CDMX & $-/-$ & ТОВ & 98.0 & $\mathrm{Y}$ & & & $\mathrm{Y}$ & & & $\mathrm{Y}$ \\
\hline CF021 & $\mathrm{F}$ & CDMX & $\Delta \mathrm{F} 508 / \Delta \mathrm{F} 508$ & тов & 90.0 & $\mathrm{Y}$ & & & & & & $\mathrm{Y}$ \\
\hline $\mathrm{CF} 022$ & M & CDMX & $-/-$ & тов & 91.0 & $\mathrm{Y}$ & & & $\mathrm{Y}$ & & & $\mathrm{Y}$ \\
\hline $\mathrm{CF} 023$ & $\mathrm{~F}$ & PUE & $-/-$ & TOB & 85.0 & $\mathrm{Y}$ & & & $\mathrm{Y}$ & $\mathrm{Y}$ & $\mathrm{Y}$ & $\mathrm{Y}$ \\
\hline CF024 & M & CDMX & $\begin{array}{c}\text { 1154insAT (1288insTA) } / \\
\text { 3232_3231delTG }\end{array}$ & AMK/AZM & 101.0 & $\mathrm{Y}$ & & & $\mathrm{Y}$ & & & $\mathrm{Y}$ \\
\hline CF025 & M & CDMX & $\Delta \mathrm{F} 508 / \Delta \mathrm{F} 508$ & ТОВ & 96.0 & $\mathrm{Y}$ & & & $\mathrm{Y}$ & & $\mathrm{Y}$ & $\mathrm{Y}$ \\
\hline CF026 & $\mathrm{F}$ & EMEX & $-1-$ & тов & 92.0 & $\mathrm{Y}$ & & & $\mathrm{Y}$ & & $\mathrm{Y}$ & $\mathrm{Y}$ \\
\hline CF027 & $\mathrm{F}$ & EMEX & $-/-$ & ТОВ & 84.0 & $\mathrm{Y}$ & & & $\mathrm{Y}$ & & & $\mathrm{Y}$ \\
\hline CF028 & $\mathrm{F}$ & EMEX & $-1-$ & - & 88.0 & $\mathrm{Y}$ & & & $\mathrm{Y}$ & & & $\mathrm{Y}$ \\
\hline CF029 & M & PUE & $-1-$ & - & 83.0 & $\mathrm{Y}$ & & & & $\mathrm{Y}$ & & $\mathrm{Y}$ \\
\hline CF030 & $\mathrm{F}$ & CDMX & $\Delta \mathrm{F} 508 / \mathrm{W} 1089 \mathrm{X}$ & TOВ & 93.0 & $\mathrm{Y}$ & & & $\mathrm{Y}$ & & & $\mathrm{Y}$ \\
\hline CF031 & $\mathrm{F}$ & GTO & $\Delta \mathrm{F} 508 / \mathrm{X}$ & ТОВ & 105.0 & $\mathrm{Y}$ & & & & & & $\mathrm{Y}$ \\
\hline CF032 & $\mathrm{F}$ & EMEX & $\Delta \mathrm{F} 508 / \mathrm{X}$ & - & 82.0 & $\mathrm{Y}$ & & & & & & $\mathrm{Y}$ \\
\hline CF033 & M & QRO & $\Delta \mathrm{F} 508 / \mathrm{X}$ & - & 80.0 & $\mathrm{Y}$ & & & $\mathrm{Y}$ & $\mathrm{Y}$ & & $\mathrm{Y}$ \\
\hline $\mathrm{CF} 034$ & M & GRO & $\Delta \mathrm{F} 508 / \mathrm{X}$ & тов & 92.0 & $\mathrm{Y}$ & & & & $\mathrm{Y}$ & $\mathrm{Y}$ & $\mathrm{Y}$ \\
\hline CF035 & M & EMEX & $\Delta \mathrm{F} 508 / \Delta \mathrm{F} 508$ & $\mathrm{AMK} / \mathrm{AZM}$ & 107.0 & $\mathrm{Y}$ & & & & & & $\mathrm{Y}$ \\
\hline CF036 & M & EMEX & $\Delta \mathrm{F} 508 / \mathrm{X}$ & - & 97.0 & $\mathrm{Y}$ & $\mathrm{Y}$ & & & & & $\mathrm{Y}$ \\
\hline CF037 & M & GTO & G542 / X & тов & 97.0 & $\mathrm{Y}$ & & & $\mathrm{Y}$ & & $\mathrm{Y}$ & \\
\hline CF038 & $\mathrm{F}$ & GTO & $-1-$ & - & 88.0 & $\mathrm{Y}$ & & & & & & $\mathrm{Y}$ \\
\hline CF039 & M & EMEX & $-1-$ & - & 83.0 & $\mathrm{Y}$ & $\mathrm{Y}$ & & $\mathrm{Y}$ & & $\mathrm{Y}$ & $\mathrm{Y}$ \\
\hline CF040 & $\mathrm{F}$ & EMEX & $-1-$ & - & 86.0 & $\mathrm{Y}$ & & & & & & $\mathrm{Y}$ \\
\hline CF041 & $\mathrm{F}$ & $\mathrm{MICH}$ & G542X/X & TOB & 96.0 & $\mathrm{Y}$ & $\mathrm{Y}$ & & & & & $\mathrm{Y}$ \\
\hline CF042 & $\mathrm{F}$ & EMEX & $-1-$ & - & 100.0 & $\mathrm{Y}$ & & & & $\mathrm{Y}$ & & $\mathrm{Y}$ \\
\hline CF043 & M & EMEX & $-/-$ & - & 99.0 & $\mathrm{Y}$ & & & & & & $\mathrm{Y}$ \\
\hline CF044 & $\mathrm{F}$ & EMEX & $\Delta \mathrm{F} 508 / \mathrm{X}$ & - & 95.0 & $\mathrm{Y}$ & & & & & $\mathrm{Y}$ & $\mathrm{Y}$ \\
\hline CF045 & $\mathrm{F}$ & EMEX & $-/-$ & - & 92.0 & $\mathrm{Y}$ & & & & & $\mathrm{Y}$ & $\mathrm{Y}$ \\
\hline CF046 & M & SIN & N1303K / X & TOB & 110.0 & $\mathrm{Y}$ & & & $\mathrm{Y}$ & & & Y \\
\hline CF047 & $\mathrm{F}$ & PUE & $-1-$ & TOB & 65.0 & $\mathrm{Y}$ & & & & $\mathrm{Y}$ & $\mathrm{Y}$ & $\mathrm{Y}$ \\
\hline CF048 & $\mathrm{F}$ & CAMP & $-1-$ & - & 102.0 & $\mathrm{Y}$ & & & & $\mathrm{Y}$ & & Y \\
\hline CF049 & M & $\mathrm{MICH}$ & $-1-$ & TOB & 106.0 & $\mathrm{Y}$ & & & & $\mathrm{Y}$ & $\mathrm{Y}$ & \\
\hline CF050 & $\mathrm{M}$ & CDMX & $-1-$ & - & 96.0 & $\mathrm{Y}$ & & & & & & $\mathrm{Y}$ \\
\hline
\end{tabular}

CF, Cystic fibrosis; M, male; F, female; Mexico City (CDMX), Morelos (MOR), Oaxaca (OAX), Durango (DGO), Mexico State (EMEX), Guanajuato (GTO), Puebla (PUE), Hidalgo (HGO), Querétaro (QRO), Guerrero (GRO), Michoacán (MICH), Sinaloa (SIN), Campeche (CAM); $\Delta$, deletion; ins, insertion; del, deletion; F, phenylalanine; $\mathrm{x}$, wild gene; -, nondetermined; TOB, Tobramycin; CXM, Cefuroxime; AMK, Amikacin; AZM, Azithromycin; $\dagger$, patient deceased. 
Table2. Bacterial pathogens isolated from 106 respiratory samples of pediatric patients with $\mathrm{CF}$.

\begin{tabular}{|c|c|c|c|c|c|c|c|}
\hline \multirow[t]{3}{*}{ Patient } & \multirow[t]{3}{*}{$P s a^{\mp}$} & \multicolumn{2}{|c|}{ FEV1 } & \multirow{2}{*}{\multicolumn{4}{|c|}{ Pathogens isolated }} \\
\hline & & \multirow[t]{2}{*}{$\%$} & \multirow[t]{2}{*}{$(y / m)$} & & & & \\
\hline & & & & $1^{\text {st }}$ & $2^{\text {nd }}$ & $3^{\text {erd }}$ & $4^{\text {th }}$ \\
\hline CF001 & III & 78.3 & $(10 / 0)$ & Sau & $\underline{P_{s a 28}}$, Sau & Sau, Stp-A & \\
\hline CF002 & II & 79.0 & $(10 / 0)$ & Psa01* & $\underline{P s a 18}$ & --- & \\
\hline CF003 & III & 34.1 & $(12 / 0)$ & $P s a 02^{\Psi}$ & $\overline{P s a 01}$, Sau & $\underline{\text { Psa } 40, \text { Sau }}$ & \\
\hline CF004 & II & 102.0 & $(13 / 0)$ & --- & $\underline{P_{s a 03}}$, Sau & & \\
\hline CF005 & I & 106.7 & $(11 / 0)$ & --- & & & \\
\hline CF006 & II & 97.0 & $(10 / 0)$ & Sau & Sau & $P s a 43^{\Psi}$, Sau, Stp-A & \\
\hline CF007 & III & 40.7 & $(17 / 0)$ & Psa0 $4^{\Psi}$, Sau & Psa04 ${ }^{\Psi *}, \mathrm{CoNS}$ & & \\
\hline CF008 $\dagger$ & III & 28.1 & $(10 / 0)$ & $\underline{\text { Psa05 }}$ & $\underline{\text { Psa34, }}$, Sau & & \\
\hline CF009 & III & 68.1 & $(9 / 0)$ & $\overline{P s a 06}^{\Psi}$ & $\overline{P s a 06}^{\Psi}$, Psa22 ${ }^{\Psi}, S a u$ & $P s a 06^{\Psi}$ & Psa06 ${ }^{\Psi}$ \\
\hline CF010 & II & 76.8 & $(18 / 0)$ & Sau & Sau & Psa41*, Sau & \\
\hline CF011 & I & 121.0 & $(8 / 0)$ & Psa07, Ecoli & Psa07, Sau & Psa07, Sau, E.coli & \\
\hline CF012 & III & 59.9 & $(17 / 0)$ & Psa08, Smarc & $\operatorname{Psa} 24^{\Psi}$ & Psa24 $4^{\Psi *}, \mathrm{Sau}$ & \\
\hline CF013 & I & 117.0 & $(8 / 0)$ & --- & Sau & Psa17* & $\mathrm{Sau}$ \\
\hline CF014 $†$ & III & 33.3 & $(9 / 6)$ & Psa $09^{\Psi}$, Sau & Psa $02^{\Psi}$, Sau, Stp-C & $\overline{P s a 09}^{\Psi}, \mathrm{Sau}$ & \\
\hline CF015 & II & 84.5 & $(17 / 0)$ & --- & $\underline{P s a 31}^{*}$ & Stp-A & \\
\hline CF016 & I & 101.0 & $(6 / 0)$ & Smarc, Koxy, Ecoli, Sau & $\overline{P s a 29}$, Sau, Ecoli & Psa47, Sau, Ecoli & \\
\hline CF017 & III & 75.7 & $(13 / 0)$ & $\underline{\text { Psa } 10}$ & & & \\
\hline CF018 & II & 101.9 & $(17 / 5)$ & 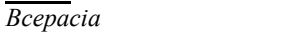 & & & \\
\hline CF019 & II & ND & $(2 / 3)$ & Sau, Ecoli* & $\underline{P s a 23}^{*}$, Sau & Sau, Ecoli* & Psa36 $6^{\Psi}, \mathrm{Sau}$ \\
\hline CF020 & I & ND & $(0 / 11)$ & $\operatorname{Psa} 11^{\Psi}$ & Ecoli & & \\
\hline CF021 & II & 94.2 & $(12 / 0)$ & --- & --- & & \\
\hline CF022 & III & 76.2 & $(9 / 0)$ & Sau & Sau & Sau & \\
\hline CF023 & III & 71.0 & $(10 / 0)$ & $\underline{P s a 12}$ & Psa37 & $\underline{P s a 42}$ & \\
\hline CF024 & III & 40.7 & $(18 / 0)$ & $\overline{P s a 13}$ & Psa35 & & \\
\hline CF025 & I & ND & $(0 / 9)$ & $P s a 15^{\Psi}, K p n$ & $\overline{S a u}$ & & \\
\hline CF026 & II & 80.7 & $(6 / 0)$ & Ecoli & & & \\
\hline CF027 & III & 72.1 & $(18 / 0)$ & Psa16 ${ }^{\Psi}$ & & & \\
\hline CF028 & III & 62.1 & $(8 / 0)$ & $\underline{P s a 17^{*}}$ & Sau, $\underline{\operatorname{Ps} a 17}$ & Sau & \\
\hline CF029 & III & 76.9 & $(13 / 0)$ & $\overline{P s a 19}$, Sau & $\mathrm{Sau}$ & & \\
\hline CF030 & II & ND & $(2 / 6)$ & ${\underline{P s a \mathrm{NT}^{*}}}^{*}$ & Sau & Sau & \\
\hline CF031 & III & 67.6 & $(11 / 0)$ & $\overline{P s a 20^{\Psi}}$ & & & \\
\hline CF032 & II & 121.1 & $(11 / 0)$ & Sau & & & \\
\hline CF033 & III & 43.0 & $(12 / 0)$ & Spt-B & & & \\
\hline CF034 & III & 103.0 & $(6 / 6)$ & Psa21 $1^{\Psi *}$, Sau & Psa $21^{\Psi}$, Sau & & \\
\hline CF035 & III & 18.1 & $(13 / 0)$ & $\operatorname{Psa} 25^{\Psi *}$ & $\operatorname{Psa} 25^{\Psi}$ & & \\
\hline CF036 & I & 116.2 & $(5 / 5)$ & $\underline{P s a 26}$, Sau, Stp-B & & & \\
\hline CF037 & I & ND & $(1 / 0)$ & $\operatorname{Psa} 27^{\Psi}$ & & & \\
\hline CF038 & III & 56.3 & $(21 / 0)$ & $\underline{P s a 30}$ & & & \\
\hline CF039 & I & ND & $(0 / 4)$ & $\overline{\text { Ecoli }}$ & --- & & \\
\hline CF040 & I & 103.7 & $(7 / 0)$ & --- & & & \\
\hline CF041 & I & ND & $(2 / 9)$ & --- & Sau & Psa39, Sau & \\
\hline CF042 & II & 92.8 & $(5 / 6)$ & $P s a 32^{\Psi}$, Sau & & & \\
\hline CF043 & I & ND & $(2 / 4)$ & Koxy, CoNS & Ecoli, Ecloac & --- & \\
\hline CF044 & I & ND & $(0 / 3)$ & Ecoli & & & \\
\hline CF045 & II & 99.3 & $(7 / 0)$ & $\underline{P s a 33}$ & & & \\
\hline CF046 & III & 96.8 & $(5 / 6)$ & $P s a 38^{\Psi}$ & $\underline{\text { Psa49 }}$ & & \\
\hline CF047 & I & 89.7 & $(6 / 5)$ & CoNS & & & \\
\hline CF048 & III & 68.2 & $(17 / 0)$ & Psa 14*, Sau & $\underline{P s a 44}$, Sau & & \\
\hline CF049 & I & ND & $(1 / 1)$ & Psa45 & Psa $48^{\Psi}$, Sau & & \\
\hline CF050 & I & ND & $(0 / 8)$ & Psa46, Ecoli, Ecloac, Kpn & & & \\
\hline
\end{tabular}

CF, Cystic Fibrosis; Sau, Staphylococcus aureus; Psa, Pseudomonas aeruginosa; Stp-A, Streptococcus group A; Stp-B, Streptococcus group B; Stp-C, Streptococcus group C; CoNS, Coagulase Negative Staphylococcus; Ecoli, Escherichia coli; Smarc, Serratia marcescens; Koxy, Klebsiella oxytoca; Bcepacia, Burkholderia cepacia; Kpn, Klebsiella pneumoniae; Ecloac, Enterobacter cloacae; NT, non-typeable; ---, None bacterial pathogen isolated, *Two different colonies that belongs to the same clone; $\uparrow$, patient deceased; I, non-colonized; II, Intermittent colonization; III, Chronical colonization. FEV1, Forced Expiratory Volume.; $(\mathrm{y} / \mathrm{m})$, age (year/month). ${ }^{\Psi}$ two phenotypes associated to chronical infection; underlined, three or four phenotypes associated with chronic infections. Bold, patients colonized with $P$. aeruginosa with phenotye of chronic infections. 
Table 3. Phenotype of $P$. aeruginosa associated with chronic infections.

\begin{tabular}{|c|c|c|c|c|c|c|}
\hline Clone & $\begin{array}{c}\text { Antimicrobial } \\
\text { drug resistance }\end{array}$ & $\begin{array}{l}\text { Biofilm } \\
\text { (Index) }\end{array}$ & $\begin{array}{c}\text { Swarming } \\
\text { (Index) }\end{array}$ & $\begin{array}{c}\text { Alginate } \\
\text { (production) }\end{array}$ & $\begin{array}{c}\text { Pigment } \\
\text { (production) }\end{array}$ & $\begin{array}{c}\text { Serum } \\
(\% \\
\text { Resistance })\end{array}$ \\
\hline PAO1 & & 1.00 & 1.00 & & PV & \\
\hline Psa01 & & 0.67 & 1.14 & & PV & 26.1 \\
\hline$P_{s a} 02^{\Psi}$ & & 0.76 & 1.46 & $\mathrm{Y}$ & PV & 7.1 \\
\hline$\underline{P s a 03}$ & MDR & 1.61 & 0.59 & & PV & 81.3 \\
\hline$P_{s a 04}$ & & 1.23 & 0.94 & $\mathrm{Y}$ & PV & 50.0 \\
\hline$\underline{P s a 05}$ & & 1.53 & 0.50 & $\mathrm{Y}$ & PV & 0.0 \\
\hline$P_{s a 06}$ & & 0.88 & 0.73 & $\mathrm{Y}$ & PM & 0.2 \\
\hline Psa07 & & 1.35 & 0.88 & & PV & 1.0 \\
\hline Psa 08 & & 1.00 & 1.81 & & PV & 0.1 \\
\hline$P s a 09^{\Psi}$ & & 0.63 & 0.00 & & PV & 0.2 \\
\hline$\underline{P s a 10}$ & & 0.59 & 0.00 & Y & PV & 0.5 \\
\hline${\overline{P s a 11^{\Psi}}}^{\Psi}$ & & 1.29 & 0.44 & & PM & 0.4 \\
\hline$\underline{P s a 12}$ & XDR & 2.36 & 0.27 & & PM & 4.7 \\
\hline Psa13 & MDR & 0.72 & 0.56 & & & 1.1 \\
\hline$\overline{P s a 14}$ & & 1.00 & 0.89 & & $\mathrm{PC}$ & 70.3 \\
\hline $\operatorname{Psa} 15^{\Psi}$ & & 2.27 & 0.06 & & PC & 0.5 \\
\hline Psa16 & & 1.07 & 0.21 & & PC & 0.8 \\
\hline Psa 17 & MDR & 0.88 & 0.60 & & PV & 12.7 \\
\hline Psa18 & MDR & 0.93 & 0.22 & & $\mathrm{~F}$ & 1.4 \\
\hline Psa19 & & 0.77 & 1.64 & & PV & 32.1 \\
\hline $\operatorname{Psa} 20^{\Psi}$ & & 0.55 & 0.17 & & PV & 5.0 \\
\hline Psa $21^{\Psi}$ & XDR & 0.30 & 0.74 & & & 85.3 \\
\hline Psa22 & & 0.70 & 0.70 & & PV & 0.3 \\
\hline Psa23 & & 0.72 & 0.70 & $\mathrm{Y}$ & PV & 69.0 \\
\hline$\overline{P s a 24}^{\Psi}$ & & 0.31 & 0.16 & & PV & 3.8 \\
\hline Psa $25^{\Psi}$ & & 0.84 & 0.11 & & & 84.1 \\
\hline Psa26 & MDR & 0.41 & 0.30 & Y & PV & 81.5 \\
\hline$\frac{1 s u 20}{\operatorname{Ps}_{s} 27^{\Psi}}$ & & 0.78 & 0.41 & & PC & 0.1 \\
\hline Psa28 & XDR & 0.95 & 0.21 & & PM & 20.9 \\
\hline$\frac{1020}{P s a 29}$ & & 0.58 & 1.53 & & PV & 88.5 \\
\hline Psa30 & MDR & 1.06 & 0.30 & $\mathrm{Y}$ & PC & 0.0 \\
\hline$\frac{P_{s a 31}}{P_{1}}$ & & 1.05 & 0.24 & $\mathrm{Y}$ & PV & 2.3 \\
\hline$\frac{P_{s a 32}}{4}$ & & 0.64 & 0.64 & & PV & 60.4 \\
\hline$\underline{P s a 33}$ & MDR & 1.34 & 0.32 & & PV & 0.1 \\
\hline Psa34 & & 1.63 & 0.33 & $\mathrm{Y}$ & PV & 1.4 \\
\hline Psa35 & MDR & 1.73 & 0.54 & & PV & 69.9 \\
\hline$P_{\text {sas6 }}$ & & 0.28 & 0.59 & $\mathrm{Y}$ & PV & 74.9 \\
\hline Psa37 & MDR & 1.94 & 0.00 & & PV & 73.1 \\
\hline$\overline{P s a 38^{\Psi}}$ & & 0.87 & 0.53 & & PV & 79.8 \\
\hline Psa39 & & 1.30 & 2.26 & & PV & 52.0 \\
\hline$\underline{P s a 40}$ & & 1.34 & 0.62 & Y & $\mathrm{PC}$ & 34.4 \\
\hline$\overline{P s a 41}$ & & 1.05 & 0.77 & & PV & 21.9 \\
\hline Psa 42 & XDR & 1.07 & 0.53 & & PV & 38.9 \\
\hline$P_{s a 43^{\Psi}}$ & & 0.90 & 0.61 & & PC & 29.6 \\
\hline$\underline{\text { Psa } 44}$ & MDR & 0.77 & 0.95 & Y & PC & 60.5 \\
\hline$\overline{P s a 45}$ & & 3.28 & 0.81 & & PV & 37.8 \\
\hline Psa 46 & & 0.69 & 1.19 & & & 59.9 \\
\hline Psa 47 & & 0.46 & 0.70 & $\mathrm{Y}$ & PV & 17.8 \\
\hline$\overline{P s a}^{\Psi}$ & & 0.95 & 1.67 & $\mathrm{Y}$ & PV & 58.0 \\
\hline Psa49 & & 1.12 & 0.52 & $\mathrm{Y}$ & PV & 66.3 \\
\hline$\frac{P_{s a \mathrm{NT}}}{}$ & & 1.13 & 0.70 & $\mathrm{Y}$ & PV & 36.1 \\
\hline
\end{tabular}

MDR, multidrug resistance [19], XDR, extensively-drug resistance [19]; Y, Yes; PV, pyoverdine; PC, pyocyanin; PM, pyomelanin; Bold numbers indicates a higher biofilm production or decreased motility. $\Psi_{\text {two }}$ phenotypes associated to chronic infections; underlined, three or four phenotypes associated to chronic infections. 
Supplementary Figure 1. Association of $P$. aeruginosa colonization with age and lung function of children with CF.

A

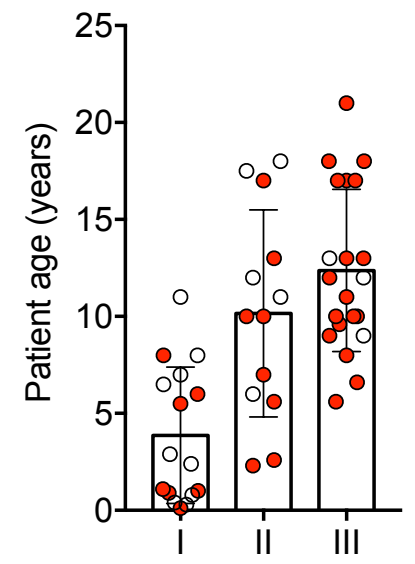

B

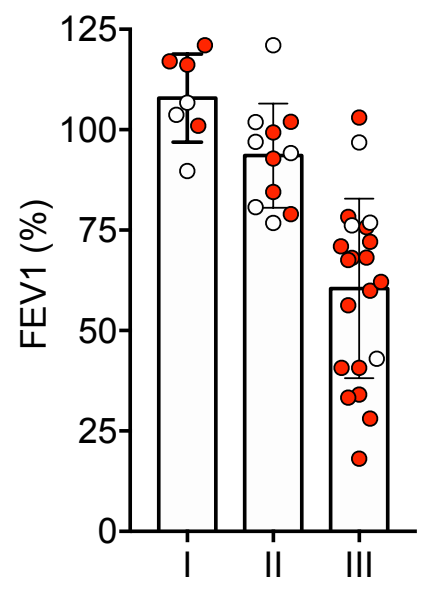

Patients enrolled in this study were classified, on the basis of having previous isolation of $P$. aeruginosa, as non-colonized (I), intermittent colonization (II) and chronic colonization (III). A) Patient age in relation to $P$. aeruginosa colonization. B) Lung function (FEV1, \%) in relation to $P$. aeruginosa colonization. White symbols indicate clones of $P$. aeruginosa without phenotype of chronic colonization and red symbols indicate clones of $P$. aeruginosa with phenotype of chronic colonization. 
Supplementary Figure 2. Antimicrobial susceptibility data of $P$. aeruginosa clones.

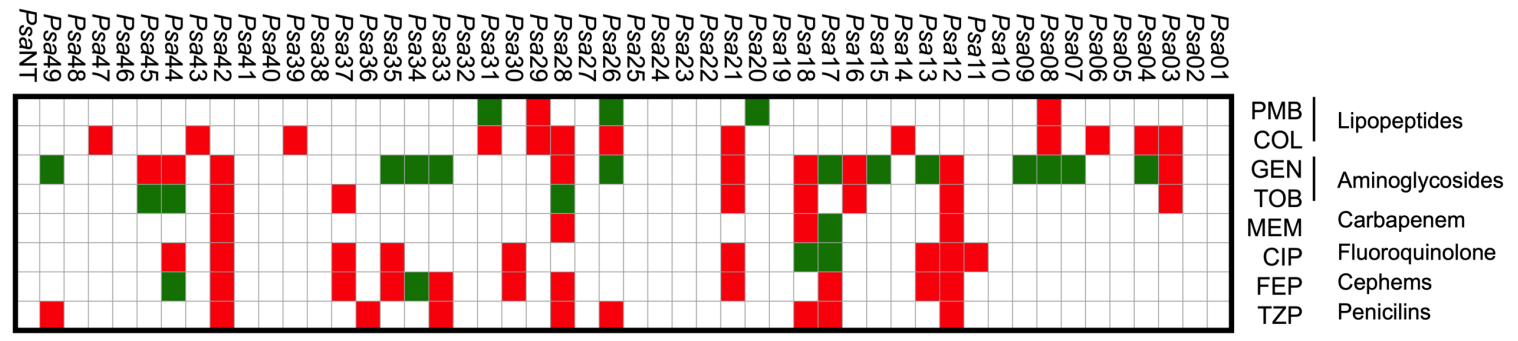

One representative isolate of each clone was assessed for the MIC determination. Broth microdilution was used for Polymyxin B and Colistin. White squares indicate susceptibility, green squares indicate intermediate susceptibility and red squares show resistance to the antibiotic assessed. The antibiotic family is indicated. 
Supplementary Figure 3. Resistance to normal human serum by $\boldsymbol{P}$. aeruginosa clones.

A

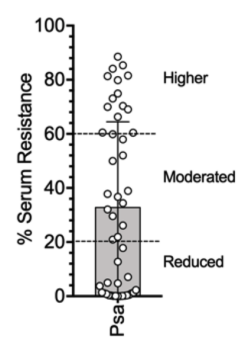

B

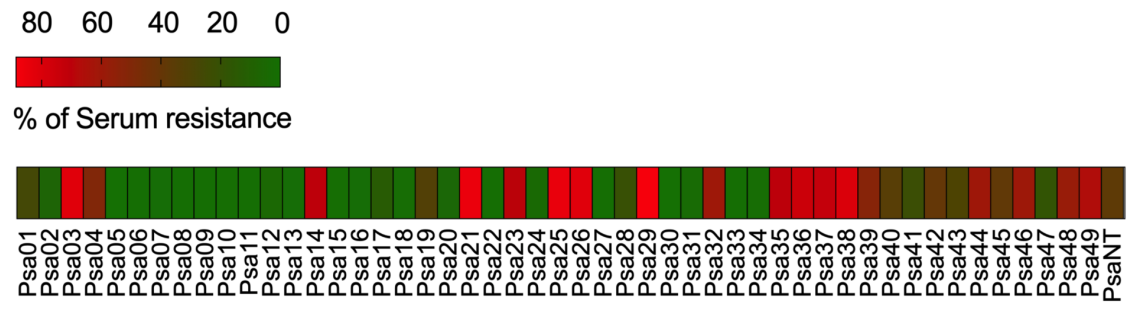

One representative isolate from each clone was assessed for resistance to the bactericidal activity of normal human serum (NHS). A) Determination of the resistance to NHS by each clone of $P$. aeruginosa, B) Heat map of susceptibility to NHS. 